\title{
Effect of Bladder Neck Preservation during Endoscopic Extraperitoneal Radical Prostatectomy on Urinary Continence
}

\author{
Jens-Uwe Stolzenburg ${ }^{a}$ Panagiotis Kallidonis ${ }^{b}$ James Hicks ${ }^{a}$ Minh Do ${ }^{a}$ \\ Anja Dietel $^{\mathrm{a}}$ George Sakellaropoulos $^{c}$ Abdulrahman Al-Aown ${ }^{b}$ \\ Evangelos Liatsikos ${ }^{\mathrm{a}, \mathrm{b}}$ \\ ${ }^{a}$ Department of Urology, University of Leipzig, Leipzig, Germany; Departments of ${ }^{b}$ Urology and cMedical Physics, \\ University of Patras, Patras, Greece
}

\section{Key Words}

Bladder neck preservation $\cdot$ Continence $\cdot$ Extraperitoneal prostatectomy $\cdot$ Positive surgical margins $\cdot$ Prostatectomy moval and at the 3-month follow-up in comparison to those without $\mathrm{BN}$ preservation, but $+\mathrm{SMs}$ were not affected by the $\mathrm{BN}$-sparing surgery.

\begin{abstract}
Objective: The current study investigates the effect of bladder neck (BN) preservation on postoperative continence and positive surgical margins (+SMs). Patients and Methods: 150 patients (group 1) who underwent BN-sparing endoscopic extraperitoneal radical prostatectomy (EERPE) and 90 patients treated with EERPE and BN resection (group 2) were retrospectively evaluated. Results: Both groups were similar for age, prostate-specific antigen and prostate size. There was no significant difference in operative time, mean blood loss or transfusion rate. Mean catheterization time was similar. The overall +SM rates were very similar at $10.7 \%$ for group 1 and $10.0 \%$ for group 2 (group 1, pT2 $=5.1 \%$ and pT3 = $30.3 \%$; group 2, pT2 $=2.9 \%$ and pT3 $=33.3 \%$ ). One of 16 patients in group 1 and 1 of 9 in group 2 had a +SM at BN. Statistically significant differences in continence were observed $24 \mathrm{~h}$ after catheter removal and 3 months postoperatively between both groups. Conclusion: BN preservation proved to have an impact on postoperative early continence of patients undergoing EERPE. Continence of patients who underwent BN preservation was improved after catheter re-
\end{abstract}

\section{Introduction}

Endoscopic extraperitoneal radical prostatectomy (EERPE) represents an established method for the treatment of localized prostate cancer. Since its introduction in 2001, we have gained considerable experience, with $>2,400$ cases treated with EERPEs [1]. The increasing experience and the report of novel anatomical data led us to technical refinements such as neurovascular bundle and puboprostatic ligaments preservation as well as the use of an energy-free technique for dissection [1-3]. Bladder neck $(\mathrm{BN})$ preservation is another refinement of the EERPE procedure.

The precise anatomy of the $\mathrm{BN}$ and its effect on continence have proven difficult to clarify. In the transverse plane, the BN is composed of two different muscles, the ventrolateral and dorsal longitudinal muscles which are positioned in an oblique direction. When the $\mathrm{BN}$ is examined in a truly transverse direction, there is a distinct circular muscle called the musculus sphincter vesicae $[2$,

\section{KARGER}

Fax +41613061234 E-Mail karger@karger.ch www.karger.com
(C) 2010 S. Karger AG, Base 0042-1138/10/0852-0135\$26.00/0

Accessible online at: www.karger.com/uin
Evangelos N. Liatsikos, MD, $\mathrm{PhD}$

Department of Urology, University of Patras Medical School

GR-26500 Rion, Patras (Greece)

Tel. +30 2610999 386, Fax +30 2610993981

E-Mailliatsikos@yahoo.com 
3]. Since incontinence represents an important postoperative issue of radical prostatectomy, the above muscle should be preserved as it represents a part of the continence mechanism. Klein [4] was the first to report a technical modification to preserve the $\mathrm{BN}$ and to improve continence. Several other investigators have concentrated on the $\mathrm{BN}$ and its preservation or reconstruction as a method to improve postoperative continence. The current study investigates the effect of $\mathrm{BN}$ preservation on continence in patients that underwent EERPE.

\section{Patients and Methods}

Retrospective evaluation of 240 patients who had undergone EERPE for localized prostate cancer between June 2005 and December 2008 was performed. A single surgeon performed all cases. The population was divided in two groups according to the $\mathrm{BN}$ method used. Group 1 included patients that underwent BN preservation $(n=150)$, while group 2 comprised patients without $B N$ preservation but with racket handle repair of the $\mathrm{BN}(\mathrm{n}=90)$ at the 12 o'clock position. Performance of $\mathrm{BN}$ preservation was defined as the absence of racket handle repair of the $\mathrm{BN}$ during the procedure.

Perioperative parameters such as operative time, transfusion and conversion rates, catheterization time, pathological results and positive surgical margin rate (+SMR) were reviewed from our surgical database. Surgical complications and ensuing additional interventions were reviewed and classified according to Clavien.

Information regarding postoperative continence was assessed $24 \mathrm{~h}$ after catheter removal, and 3, 6 and 12 months after EERPE. All patients were followed up for $\geq 1$ year. Urinary continence was evaluated using the International Continence Society questionnaire. Postoperative continence was defined as the absence of need for pads or the use of one pad daily for security. Occasional urine leakage requiring 2-3 pads/day was classified as mild stress incontinence during the day with normal activity, including moderate sporting activity like walking. Patients requiring $>3$ pads daily were considered as incontinent.

Postoperative cystography was performed in all patients on the 5 th postoperative day. If the anastomosis and reconstructed bladder site (in group 2) were watertight, the catheter was removed. In case of leakage, catheterization (5-10 days) and cystography were repeated.

Any differences in continence between both groups were tested for significance using Fisher's exact test in cases of one degree of freedom, i.e. when the corresponding contingency tables were $2 \times 2$, and the $\chi^{2}$ test otherwise. Significance level was set at 0.05 .

\section{Results}

The patients in both groups were similar for age, prostate-specific antigen (PSA) and prostate size. Perioperative parameters such as operative time, mean blood loss or transfusion rate were similar. The mean time of cath-
Table 1. Patient data

\begin{tabular}{lcc}
\hline Characteristics & $\begin{array}{l}\text { BN preservation } \\
\text { (group 1) }\end{array}$ & $\begin{array}{l}\text { No BN preservation } \\
\text { (group 2) }\end{array}$ \\
\hline Patients, $\mathrm{n}$ & 150 & 90 \\
Age, years & $61.3(41-75)$ & $61.6(47-81)$ \\
PSA, ng/ml & $8.22(2.3-36.3)$ & $9.23(0.6-56)$ \\
Operative time, min & $131.7(65-225)$ & $136.1(75-330)$ \\
Blood loss, ml & $275(20-750)$ & $261(40-750)$ \\
Transfusion rate, \% & 2.0 & 1.0 \\
Prostate weight, g & $43.3(20-105)$ & $45.7(16-112)$ \\
Catheterization, days & $6.1(4-23)$ & $6(4-20)$ \\
$\quad>14$ days, \% & 1.30 & 3.30 \\
\hline
\end{tabular}

eterization did not differ between both groups, but more patients in group $2(3.30 \%)$ required a catheter for $>14$ days compared with group 1 (1.30\%; table 1$)$.

Group 1 patients had a lower postoperative Gleason grade but similar overall pathological stage (table 2). Overall + SMRs were very similar at $10.7 \%$ for group 1 and $10.0 \%$ for group 2. Patients with pT2 and pT3 disease in group 1 had a + SMR of 5.1 and $30.3 \%$, respectively. In group 2, the +SMR for pT2 and pT3 patients was 2.9 and $33.3 \%$, respectively. Of the 16 patients in group 1 with $+\mathrm{SM}$, only 1 was located at BN (12 at the apex and 3 at other locations). In group 2 , only 1 of 9 patients had $+S M$ at $\mathrm{BN}$ (6 at the apex and 2 at other locations; table 2). At 12 months, $91.7 \%$ of patients in group 1 and $91.3 \%$ in group 2 had PSA $<0.1 \mathrm{ng} / \mathrm{ml}$.

Continence was assessed by recording the pad usage $24 \mathrm{~h}$ after catheter removal, and 3, 6 and 12 months postoperatively. Table 3 demonstrates postoperative continence data. One day after catheter removal, $19.9 \%$ of patients in group 1 were continent, 50\% used 2-3 pads and $30.1 \%$ required $>3$ pads. In the group without $\mathrm{BN}$ preservation, $9.4 \%$ were continent, $50.6 \%$ needed $2-3$ pads and $40 \%>3$ pads. In both groups, continence improved significantly with time. At 3 months, $73.3 \%$ of group 1 and $61.3 \%$ in group 2 were continent. Continent patients represented $86.5 \%$ of group 1 and $80.6 \%$ of group 2 at 6 months. Mild stress incontinence was reported by 8.1 and $14.5 \%$ in groups 1 and 2, respectively. Incontinence was noted in $5.4 \%$ of group 1 and $4.9 \%$ of group 2 patients. At 12 months, 93.5 and $91.5 \%$ of group 1 and group 2 patients were continent, respectively. Significantly improved continence was observed in group 1 at the time of catheter removal $(\mathrm{p}=0.038)$ and 3 months postoperatively $(\mathrm{p}=0.045)$. 
Table 2. Pathology results

\begin{tabular}{lcl}
\hline & $\begin{array}{l}\text { BN preservation } \\
\text { (group 1) }\end{array}$ & $\begin{array}{l}\text { No BN preservation } \\
\text { (group 2) }\end{array}$ \\
\hline $\begin{array}{l}\text { Postoperative Gleason score, } \% \\
4-6\end{array}$ & 45.5 & \\
7 & 22.0 & 38.2 \\
$8-10$ & 32.5 & 31.6 \\
\hline Overall stage & & 30.2 \\
pT2 & $117(78 \%)$ & $69(76.7 \%)$ \\
$\quad$ pT2a & $17(11.3 \%)$ & $8(8.9 \%)$ \\
$\quad$ pT2b & $4(2.7 \%)$ & $6(6.7 \%)$ \\
pT2c & $96(64 \%)$ & $55(61.1 \%)$ \\
pT3 & $33(22 \%)$ & $21(23.3 \%)$ \\
$\quad$ pT3a & $19(12.7 \%)$ & $15(16.6 \%)$ \\
pT3b & $14(9.3 \%)$ & $6(6.7 \%)$ \\
\hline +SM, R1 (overall) & $16(10.7 \%)$ & $9(10.0 \%)$ \\
BN & 1 & 1 \\
Apex & 12 & 6 \\
Other & 3 & 2 \\
pT2 & $5.1 \%$ & $2.9 \%$ \\
pT3 & $30.3 \%$ & $33.3 \%$ \\
\hline
\end{tabular}

\section{Discussion}

EERPE and laparoscopic radical prostatectomy enlarge the operative field and enable close dissection of the BN and its preservation, thus improving early postoperative continence after radical prostatectomy and therefore quality of life [5]. In the current study, patients treated with BN preservation revealed an advantage with respect to early continence. Nevertheless, no statistically significant difference was observed 6 and 12 months postoperatively.

Controversy exists in the current literature regarding $\mathrm{BN}$ preservation. The reported advantage of earlier return to continence should be balanced against the possibility of an increased +SMR. Shelfo et al. [6] studied 365 patients having BN-preserving radical retropubic prostatectomy (RRP) and observed that $88 \%$ were continent at 6 months with $7 \%$ having a $+\mathrm{SM}$ at $\mathrm{BN}$. Poon et al. [7] retrospectively studied 101 patients having BN-sparing RRP and compared continence rates with patients having $\mathrm{BN}$ reconstruction either with a racket handle repair or an anterior bladder tube reconstruction. High continence rates $\geq 93 \%$ were achieved regardless of the BN approach used. No significant difference between each technique was observed in terms of continence. However, they also observed +SMs at the $\mathrm{BN}$ in $27.4 \%$ of the $\mathrm{BN}$ preservation cases, which was not significantly different to the group without $\mathrm{BN}$ preservation [7]. An earlier return to continence was observed
Table 3. Postoperative continence

\begin{tabular}{lccc}
\hline Continence & $\begin{array}{l}\text { Pads } \\
\mathrm{n}\end{array}$ & $\begin{array}{c}\text { BN preserva- } \\
\text { tion (group 1) }\end{array}$ & $\begin{array}{l}\text { No BN preser- } \\
\text { vation (group 2) }\end{array}$ \\
\hline After catheter removal & $0-1$ & 19.9 & 9.4 \\
& $2-3$ & 50.0 & 50.6 \\
& $>3$ & 30.1 & 40.0 \\
$\chi^{2}$ test $(\mathrm{p}=0.038)$ & & & \\
\hline At 3 months & $0-1$ & 73.3 & 61.3 \\
& $2-3$ & 16.8 & 27.5 \\
& $>3$ & 9.9 & 11.2 \\
$\chi^{2}$ test $(\mathrm{p}=0.045)$ & & & \\
\hline At 6 months & $0-1$ & 86.5 & 80.6 \\
& $2-3$ & 8.1 & 4.9 \\
& $>3$ & 5.4 & \\
$\chi^{2}$ test $(\mathrm{p}=0.416)$ & & & 61.5 \\
\hline At 12 months & $0-1$ & 93.5 & 2.1 \\
& $2-3$ & 4.8 & \\
$\chi^{2}$ test $(\mathrm{p}=0.92)$ & & 1.7 & \\
\hline
\end{tabular}

by Lowe [8] in BN preservation patients compared with $\mathrm{BN}$ reconstruction cases. Continence was reported in 23.3 and $11.2 \%$ of patients at 1 month, 62 and $44 \%$ at 3 months, and 70 and $82 \%$ at 6 months, respectively. No difference was observed 12 months after the procedure. Deliveliotis et al. [9] reported similar experience with improved early continence but no long-term difference.

The potential increase in +SMR is one of the main concerns regarding preservation of the $\mathrm{BN}$. An early open RRP series reported +SM in 35-40\% [10]. Nevertheless, the surgical techniques have been refined in open, laparoscopic and robotic surgery to yield much lower +SMRs. The review of 2,400 patients who underwent EERPE found a +SMR of 8 and $35.6 \%$ for $\mathrm{pT} 2$ and $\mathrm{pT} 3$ prostate cancers, respectively [11]. These results are similar to other large series and to open and robotic prostatectomy [1214]. Srougi et al. reported a randomized trial studying the BN preservation in open retropubic radical prostatectomy. The latter study was stopped after including 70 patients since +SMs (10\%) were only found at the BN site of $\mathrm{BN}$ preservation cases. Moreover, continence with $\mathrm{BN}$ preservation was not reported to be significantly improved [15]. Bianco et al. [11] reported +SMs at the BN in only $2 \%$ of patients during BN-sparing RRP. The study included 675 patients that were retrospectively evaluated. In general, the improvement in +SMRs observed in recent studies could be attributed to better surgical tech- 
niques as well as earlier tumor detection in the era of PSA testing and screening.

The results of the current study reveal an advantage of $\mathrm{BN}$ preservation over $\mathrm{BN}$ reconstruction approaches in terms of immediate/early postoperative continence. BN preservation provides improved early continence, which is reflected by the higher percentage of continent and mildly incontinent patients after catheter removal and 3 months postoperatively. The continence rates of the patients who underwent the $\mathrm{BN}$ preservation procedure were higher during the remaining follow-up schedule without achieving statistical significance.

The oncological outcome of the EERPE procedure regarding the presence of $+\mathrm{SMs}$ was not compromised with the BN-sparing procedure. In fact, the overall +SMRs were similar for both groups. Specifically, 10.7 and 10\% of the cases in groups 1 and 2 were observed to have + SMs, respectively. BN was the site for + SM in 1 of 16 cases in the $\mathrm{BN}$ preservation group and in 1 of 9 cases of the bladder reconstruction group. As a result, the $\mathrm{BN}$ approach during EEPRE does not have an impact on the +SMs observed postoperatively.

There are several limitations to this study. Although the data on our patients are collected prospectively, the study is retrospective in nature and patients are not randomized. The BN approach was decided intraoperatively. Thus, it is possible that patients were selected according to individual features and technical considerations encountered intraoperatively. Cases of large prostate, prominent middle lobe or more difficult dissection would likely be spared the BN preservation approach. Even though the current study does not address the impact of these factors, the perioperative parameters such as operative time, blood loss and the size of the prostate as well as postoperative follow-up parameters such as continence did not vary across the study groups and EERPE patients in our experience [1].

Another problem was the definition and quantification of BN preservation. Data regarding bladder neck preservation or reconstruction were recorded in the operative notes, but the issue of accurate recording remains unclear since the definition of BN preservation is subjective and based on the absence of racket handle repair of the $\mathrm{BN}$ and the direct suturing of the $\mathrm{BN}$ on the urethra. In an attempt to eliminate any subjective biases due to individual reporting of the $\mathrm{BN}$ approach used, we included cases that were operated by the same surgeon.

In conclusion, $\mathrm{BN}$ preservation proved to have a postoperative effect on early continence in EERPE-treated patients. Continence of patients who underwent BN preservation was improved after catheter removal and at the 3-month follow-up in comparison to those without $\mathrm{BN}$ preservation, but $+\mathrm{SMs}$ were not influenced by the performance of $\mathrm{BN}$ preservation.

\section{References}

1 Stolzenburg JU, Kallidonis P, Do M, et al: Endoscopic extraperitoneal radical prostatectomy: evolution of the technique and experience with 2400 cases. J Endourol 2009; 23:1467-1472.

-2 Dorschner W, Stolzenburg JU, Dietrich F: A new theory of micturition and urinary continence based on histomorphological studies. 2. The muscularis sphincter vesicae: continence or sexual function? Urol Int 1994;52: 154-158.

-3 Dorschner W, Stolzenburg JU, Neuhaus J: Structure and function of the bladder neck. Adv Anat Embryol Cell Biol 2001;159:IIIXII, 1-109.

$\checkmark 4$ Klein EA: Early continence after radical prostatectomy. J Urol 1992;148:92-95.

5 Liatsikos E, Assimakopoulos K, Stolzenburg JU: Quality of life after radical prostatectomy. Urol Int 2008;80:226-230.

$\checkmark 6$ Shelfo SW, Obek C, Soloway MS: Update on bladder neck preservation during radical retropubic prostatectomy: impact on pathologic outcome, anastomotic strictures, and continence. Urology 1998;51:73-78.
7 Poon M, Ruckle H, Bamshad BR, Tsai C, Webster R, Lui P: Radical retropubic prostatectomy: bladder neck preservation versus reconstruction. J Urol 2000;163:194-198.

8 Lowe BA: Comparison of bladder neck preservation to bladder neck resection in maintaining postprostatectomy urinary incontinence. Urology 1996;48:889-893.

$\checkmark$ Deliveliotis C, Protogerou V, Alargof E, Varkarakis J: Radical prostatectomy: bladder neck preservation and puboprostatic ligament sparing - effects on continence and positive margins. Urology 2002;60:855-858.

$\checkmark 10$ Gomez CA, Soloway MS, Civantos F, et al: Bladder neck preservation and its impact on positive surgical margins during radical prostatectomy. Urology 1993;42:689-693.

$\checkmark 11$ Bianco FJ, Grignon DJ, Sakr WA, Shekarriz B, Upadhyay J, Dornelles E, et al: Radical prostatectomy with bladder neck preservation: impact of a positive margin. Eur Urol 2003;43:461-466.
12 Guillonneau B, el-Fettouh H, Baumert H, et al: Laparoscopic radical prostatectomy: oncological evaluation after 1,000 cases at Montsouris Institute. J Urol 2003;169:12611266.

13 Touijer K, Secin FP, Cronin AM, Katz D, Bianco F, Vora K, Reuter V, Vickers AJ, Guillonneau B: Oncologic outcome after laparoscopic radical prostatectomy: 10 years of experience. Eur Urol 2009;55:1014-1019.

- 14 Ficarra V, Novara G, Artibani W, Cestari A, Galfano A, Graefen M, Guazzoni G, Guillonneau B, Menon M, Montorsi F, Patel V, Rassweiler J, Van Poppel H: Retropubic, Laparoscopic, and robot-assisted radical prostatectomy: a systematic review and cumulative analysis of comparative studies. Eur Urol 2009;55:1037-1063.

15 Srougi M, Nesrallah LJ, Kauffmann JR, Nesrallah A, Leite KR: Urinary continence and pathological outcome after bladder neck preservation during radical retropubic prostatectomy: a randomized prospective trial. J Urol 2001;165:815-818. 